\title{
Analysis of Employee Turnover Cost and Impact on Economic Benefits
}

\author{
Zhang Li-yan Rong Xin-yan \\ (Qinhuangdao Institute of Technology; Hebei Qinhuangdao 066100 China)
}

Keywords: turnover cost; early warning; human resource management; economic benefit

\begin{abstract}
The cost of enterprise employees turnover has big impact on the enterprise economic growth, so the relationship of enterprise employee turnover and the enterprise economic is researched, and the risk warning assessment of employee turnover is realized. At present, the mathematical model of enterprise economic growth and the employee turnover does not have a valid quantitative scheme, it hard to have early warning analysis of employee turnover. An improved employees turnover intention multiple linear regression mathematical model is proposed based on largest Lyapunov exponent prediction algorithm, the risk early warning evaluation system of enterprise employee turnover is established, largest Lyapunov exponent algorithm is taken for employee turnover cost prediction, the impact on the economic efficiency of enterprises is analyzed, the employee turnover cost and enterprise economic benefit attenuation model is constructed, employee turnover cost data is extracted, the enterprise economic growth data feature is extracted, the feature fusion processing is implemented. Turnover Trend Degree parameter is defined, the employee turnover cost and the economic benefit are predicted, and the mathematical relationship model is constructed. Simulation results show that, the system can analyze the employee turnover trend degree quantitatively, the employee turnover cost prediction accuracy is improved, and it can accurately describe the costs of economic growth and enterprise the decay of the economic impact of the mathematical relationship. The value is consistent with the actual condition, can effectively grasp the company employee turnover limits and make the early warning, promote the company make related reform and rectification, and promote enterprise economic growth. It also has good application value in the field of human resources management.
\end{abstract}

\section{Introduction}

In this world, talent resource is the first resource, science and technology is the first productivity. Talent and labor shortage has become an important problem need to be solved, the occurrence and development of labor shortage is serious, it is a big difficulty the enterprise management must face, employee turnover and impact on the enterprise benefit and risk assessment has become an important research subject of enterprise management. The development of today's enterprise is more dependent on the agglomeration of professional talents, agglomeration of professional talents, specialized knowledge is more centralized, professional requirements are high, staff training of the enterprise is tedious, it takes hard work and effort to cultivate the human resource, the turnover cost of employees is big, how to retain talent is foundation for enterprise development, and it is the key to determine the enterprise economic benefits performance. Employee turnover risk should be predicted effectively, it carries on the quantitative assessment of it, the development of enterprises is like stepping stones across the river. However, as a mature enterprise, it needs to comprehensively and objectively look at the risk problem of employee turnover, face the difficulty and seek for the scientific decision-making[1].

Employee resignation and turnover is and inevitable problem need to face for any enterprise, according to traditional thinking, the staff of the enterprise is an antagonistic event, with rejection and disgust thought, eventually led to the vicious spiral, unfavorable to the development of enterprises. It is not benefit to the development of the society and county[2]. Traditionally, turnover mathematical model is scare, enterprise employees turnover mathematical model is absent, risk analysis of employee does not have a valid quantitative model, the staff of the enterprise is sad and blind obedience. It is unable to quantitatively analyze the advantages and disadvantages of business impact on employee turnover, it cannot solve early warning and predict employee turnover from 
scientific and quantitative angle. It is unfavorable to the development of enterprises[3].

To solve this problem, an improved employees turnover intention multiple linear regression mathematical model is proposed based on largest Lyapunov exponent prediction algorithm, the risk early warning evaluation system of enterprise employee turnover is established, largest Lyapunov exponent algorithm is taken for employee turnover cost prediction. Simulation results show that, the system can analyze the employee turnover trend degree quantitatively, the employee turnover cost prediction accuracy is improved, and it can accurately describe the costs of economic growth and enterprise the decay of the economic impact of the mathematical relationship. It also has good application value in the field of human resources management.

\section{Turnover risk early warning evaluation and employee turnover cost function index}

Currently, the employee management of the major enterprise is focus more on the basic information management of staff, such as age, place of origin, statistical management, professional education, marital status, business skills, performance appraisal, salary and other aspects, these basic information can provide relevant information for the enterprise personnel support, and the employee turnover risk early warning evaluation system is constructed based on the basic information extraction, the basic information management of employee has a positive supporting role to improve the enterprise human resources management. However, these data and information from the front only reflect the normal information of employees, can not reflect the staff of the exchange, turnover and job hopping. The employee turnover has influence on the enterprise and the evaluation from another surface, eventually led to the management lag and passive[4]. Once the employee turnover flood occurred, it will bring immeasurable losses to the enterprise, so the prediction and risk assessment of employee turnover behavior should be researched. Based on this, the system design of employee turnover risk assessment and prediction system is designed, and the cost of enterprise employees turnover has big impact on the enterprise economic growth, so the relationship of enterprise employee turnover and the enterprise economic is researched, the main functions of the system contains: configuration management, personal risk management, employee turnover demand survey, and risk analysis of turnover, early warning assessment analysis and processing subsystem, etc. Function block diagram of employee turnover risk warning assessment and prediction system is shown in Figure 1.

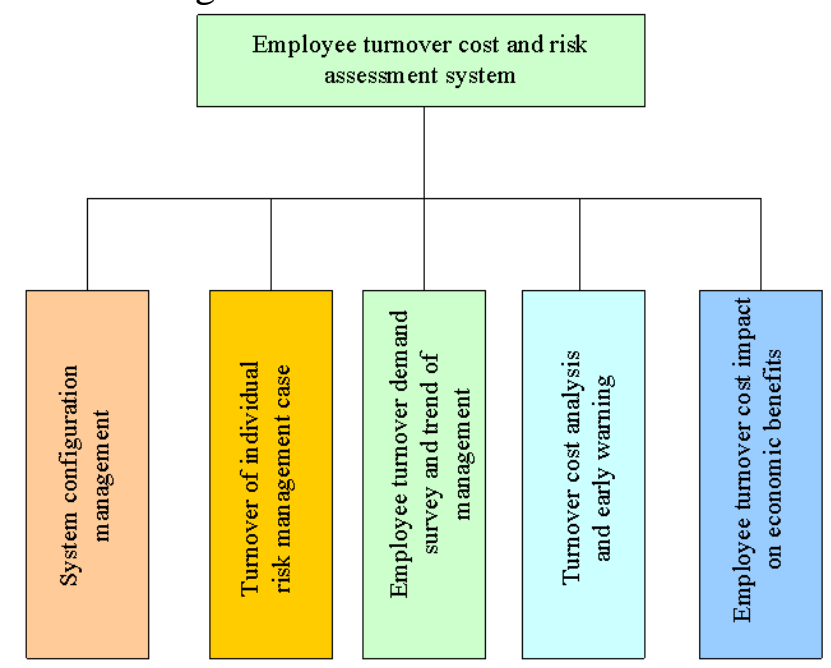

Figure 1 Function block diagram of employee turnover risk warning assessment and prediction system

System model is established, the impact on the economic efficiency of enterprises is analyzed, the employee turnover cost and enterprise economic benefit attenuation model is constructed, however, some soft information of human resource department is easily overlooked, improve the human resources department risk prediction and risk aversion ability. Risk warning assessment system is proposed in this paper, the overall turnover business needs are taken as an example, carries on the system model construction. 
The external system interface is set to achieve docking and set access of external human resources information management, staff basic information management system is established, and the related information sharing information format conversion is provided, questionnaire template setting is used to achieve employee survey system, the function such as create, edit, access and classification of employee turnover are realized in the system, set risk quantification factor as 1-10; Mathematical modeling prediction method risk assessment prediction and warning setting module is proposed, the basic signal information is collected in the before, Employee turnover risk cost and business economic benefits loss are evaluated and predicted.

In this paper, the employees turnover intention multiple linear regression mathematical model is proposed based on largest Lyapunov exponent prediction algorithm, the risk early warning evaluation system of enterprise employee turnover is established, with risk early-warning management system settings, on the next step, distribution and reasonable calculation of recruit staff and related training is taken, to evaluate the turnover possibility, risk probability analysis is realized. With quantitative analysis on the employees turnover cost, the threshold is set based on turnover cost factor, the economic benefits will be affected, early warning report function of employee turnover can be realized.

\section{Mathematical model of employee turnover cost impact on economic benefits}

\section{Turnover intention early warning model and mathematical modeling}

According to the analysis of the above functions, overall design of employee turnover risk prediction and early warning assessment system is designed through risk management console, based on the questionnaire survey and data analysis, sharing of information service and resources, and it can be applied in the development of the human resources management and service. Among them, risk prediction evaluation engine is the core and key of the system, through the prediction algorithm, statistical test and analysis of employee turnover and economic benefits can be obtained. In this section, the mathematical model of employee turnover cost impact on economic benefits, degree of turnover intention is defined as ${ }^{\varphi}$, it is a measure of employee turnover intention factor variable, the study found that the degree of turnover intention has positive correlation to specific behavior of turnover, the correlation coefficient is 0.52 , by predicting the degree of turnover intention, it can be specific to predict the actual departure from office conduction, reached on the purpose of risk early warning. Employee turnover early-warning is divided into three stages: the consciousness of turnover measure, employee turnover tendency and reasons, and existing problem and treatment[5].

The factors such as questionnaire, turnover intention degree calculation, measures to deal with the work are implemented. In this paper, the degree of staff turnover is divided into three levels as red, green, orange signal warning. Measure quantitative analysis is taken on the tendency of degree, relationship of interval value of turnover intention degree and the warning level is shown in Table 1, when the alert level to orange signal warning, , said the loss of human resources in the grim situation, need to take control and improvement measures, otherwise it will cause the loss of enterprises performance, while the warning level is red warning, it shows staff turnover enterprises is quite severe, management should be the key factors of employee turnover, it should taken the reform means.

Table 1 Correspondence relationship of turnover intention degree and warning level

\begin{tabular}{lll}
\hline Number & Turnover intention degree $\varphi$ & Warning level \\
\hline 1 & $(0,2)$ & Green \\
2 & {$[2,4)$} & Orange \\
3 & {$[4, \infty)$} & Red \\
\hline
\end{tabular}

Based on the multiple linear regression model, improved employees turnover intention multiple linear regression mathematical model is proposed, assumed that:

(a) Turnover intention and related factors are linear correlation; 
(b) Turnover cost and economic influence factors are independent of each other

The in multivariate linear regression mathematical model of staff turnover cost expression can be described as:

$$
R_{2}^{T} R_{2}=\left\{X_{d+1}, X_{d+2}, \cdots X_{d+m}\right\}\left\{X_{d+1}, X_{d+2}, \cdots X_{d+m}\right\}^{T}
$$

Where, the $\left\{X_{d+1}, X_{d+2}, \cdots X_{d+m}\right\}$ is the related factors of turnover cost, $\left\{X_{d+1}, X_{d+2}, \cdots X_{d+m}\right\}^{T}$ are the perturbation variables, such as the global financial turmoil, employee accident, etc. On the basis of the model, the maximum Lyapunov exponent prediction algorithm is proposed to predict the employees turnover cost, the turnover value and enterprise performance trend analysis can be predicted too, operation process of employee turnover early-warning system is shown in Figure 2.

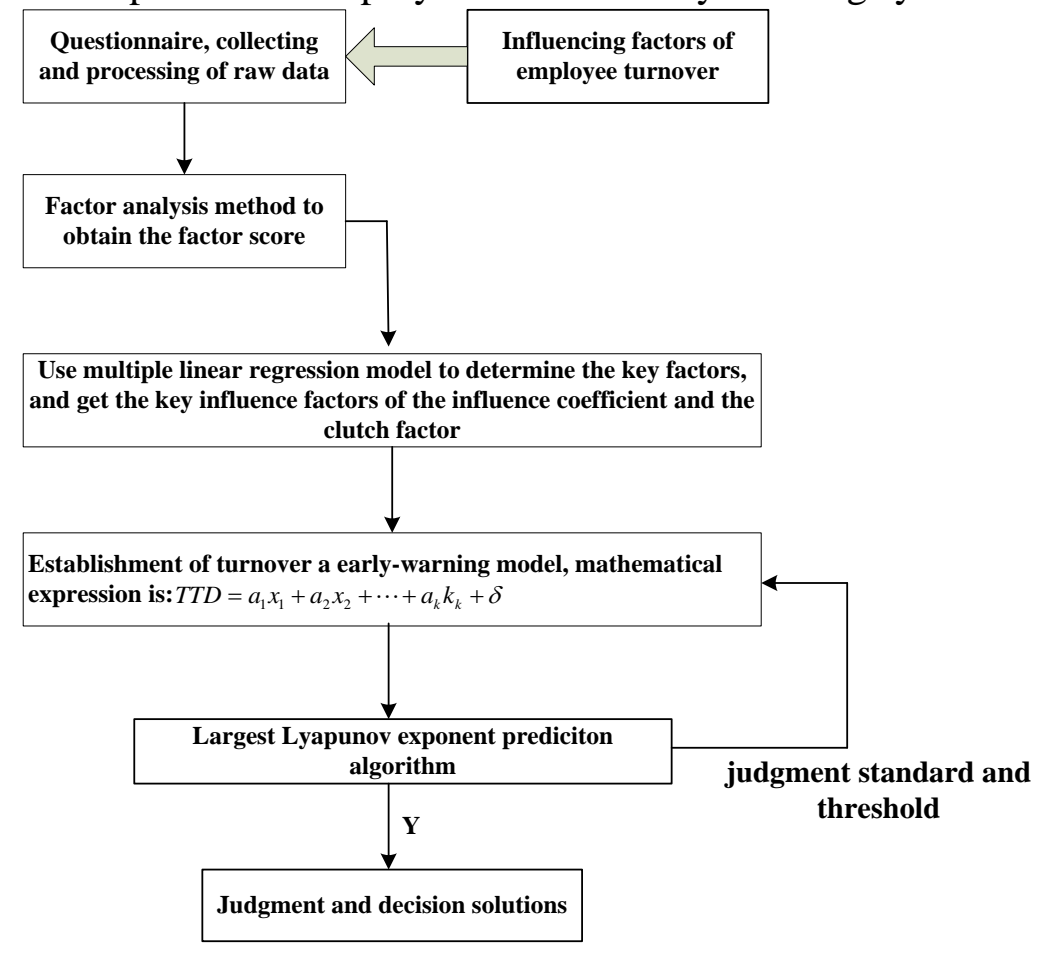

Figure 2 Operation diagram of employee turnover const warning and economic benefit growth analysis system

\section{Turnover and economic benefit effects model based on Lyapunov exponent prediction algorithm}

An improved employees turnover intention multiple linear regression mathematical model is proposed based on largest Lyapunov exponent prediction algorithm, the effect on the enterprise economic benefits is analyzed, turnover cost and enterprise attenuation model are constructed.

Employee turnover cost data are sampled based on questionnaire investigation, data information degree of prediction analysis data prediction in time $t$ is $\operatorname{DCT}\left(x_{t}\right)=p\left(x_{t} \mid d_{0, \cdots, t}\right)$, the number is $N$. $V \in R^{m \times m}$, it represents the random sample data collection analysis set, then the employee turnover cost analysis set is defined as:

$$
S_{t}=\left\{s_{t}^{j}\left(x_{t}^{j}, w_{t}^{j}\right) ; i=1,2, \cdots, N\right\}
$$

Where, $x_{t}$ is the Lyapunov exponent spectrum, $w_{t}$ is the corresponding weight vector of the enterprise economic growth series, orthogonal vector solution $V=\left[V_{1}, V_{2}, \cdots, V_{m}\right] \in R^{m \times m}$. Extraction of decomposition to reduce the deep dimension feature for:

$$
x_{k}=f\left\{x_{k-1}, u_{k-1}, w_{k-1}\right\}
$$

Where, $u_{k}$ is the input model of employee turnover cost, such as prediction and analysis number, frequency and other parameters. $w_{k}$ is the statistics value of employee turnover cost. Get the employee turnover cost prediction equation for the wide area measurement and analysis:

$$
z_{k}=h\left(x_{k}, M, v_{k}\right)
$$


Where, $M$ is normal state of employee turnover cost forecast analysis system, $v_{k}$ is the enterprise economic growth attenuation perturbation analysis data.

The enterprise economic growth data feature is extracted, the feature fusion processing is taken, the fusion characteristic value is $\sum=\operatorname{diag}\left(\sigma_{1}, \sigma_{2}, \cdots, \sigma_{m}\right) \in R^{m \times m}$. In feature space, the orthogonal decomposition result of Lyapunov exponent spectrum is:

$$
R^{T} R=\left[\begin{array}{ll}
V_{s} & V_{n}
\end{array}\right]\left[\begin{array}{cc}
\sum_{s} & 0 \\
0 & \sum_{n}
\end{array}\right]\left[\begin{array}{ll}
V_{s} & V_{n}
\end{array}\right]^{T}
$$

To obtain data prediction sequence confidence value:

$$
H_{k}\left(x_{t}\right)=p\left(x_{t} \mid z_{t}, u_{t-1}, z_{t-1}, \cdots, u_{0}, z_{0}\right)
$$

Thus, the employee turnover cost and the economic benefit are predicted, and the mathematical relationship model construction is completed.

\section{Simulation result and analysis}

In order to test the performance of this model, the simulation is taken, in the simulation, the China Deli electrical limited company is taken as the research object, the company is a local company to research electrical equipment development design and production and sales company, so the relevant information has a certain reference. The original research data are collected based on by means of questionnaire and investigation, investigation object is the basic characteristics of the company's core staff, involving various ages and various types, the staff have different educational levels. Factor analysis was conducted on the questionnaire results, by using orthogonal method for rotation, the questionnaire of 22 questions are compressed as 10 factors, the eigenvalue contribution rate can describe the enterprise employees turnover cost, eigenvalue contribution rate results are presented in Table 2.

Table 2 Factor analysis of eigenvalue and contribution rate interpretation table

\begin{tabular}{l|lll}
\hline $\begin{array}{l}\text { Factor } \\
\text { number } a_{\mathrm{i}}\end{array}$ & $\begin{array}{l}\text { Eigenv } \\
\text { alue }\end{array}$ & $\begin{array}{l}\text { Variance } \\
\text { contribution rate }\end{array}$ & $\begin{array}{l}\text { Cumulative } \\
\text { contribution rate }\end{array}$ \\
\hline 1 & 2.525 & 11.563 & 11.236 \\
\hline 2 & 2.426 & 11.123 & 22.365 \\
\hline 3 & 2.205 & 9.265 & 31.236 \\
\hline 4 & 2.104 & 9.154 & 42.365 \\
\hline 5 & 1.660 & 7.236 & 53.364 \\
\hline 6 & 1.288 & 5.969 & 59.364 \\
\hline 7 & 1.192 & 5.436 & 63.329 \\
\hline 8 & 1.144 & 5.324 & 70.364 \\
\hline 9 & 1.102 & 5.210 & 73.364 \\
\hline 10 & 1.064 & 4.897 & 74.321 \\
\hline
\end{tabular}

On the basis of the analysis of eigenvalue and contribution rate, the employee turnover const is predicted, and the enterprise employees turnover cost prediction simulation curve and the corresponding enterprise economic growth simulation curve are shown in Figure 3. 


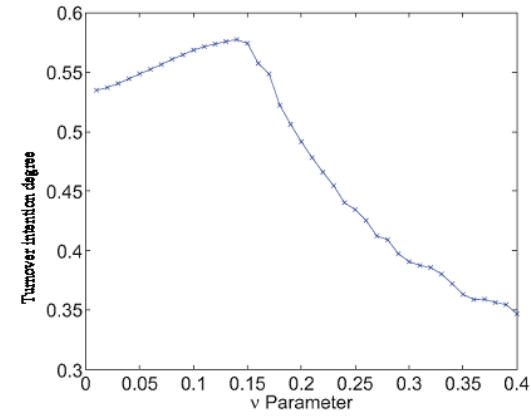

(a) Enterprise employees turnover cost prediction

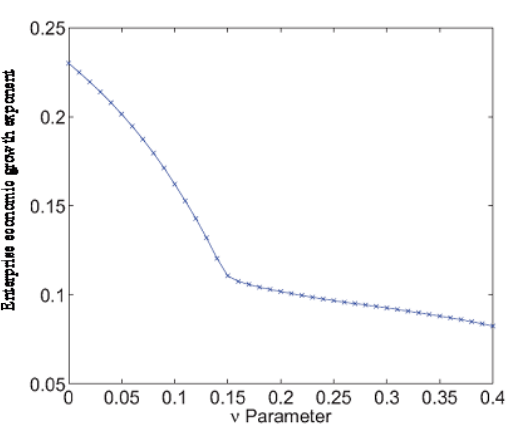

(b) Enterprise economic growth simulation

Figure 3 Relationship of enterprise employees turnover cost and economic growth exponent

From the figure 3, it shows that with the employee turnover, it will lead to economic benefits growth is falling, degree of turnover intention value is 3.467896, according to the conclusion from table 1, the company's loss of staff turnover tendency has orange signal warning, it needs to cause the attention of management, according to the actual staff on an annual turnover rate 3.3\%, compared to this value, the employee turnover characterization is in accord with the actual situation. Based on this, the electric company currently needs corporate strategic planning, employee occupation planning and the organizational structure of enterprises should be reformed, to prevent further loss of talents, improve the economic growth level.

\section{Conclusions}

An improved employees turnover intention multiple linear regression mathematical model is proposed based on largest Lyapunov exponent prediction algorithm, the risk early warning evaluation system of enterprise employee turnover is established, largest Lyapunov exponent algorithm is taken for employee turnover cost prediction, the impact on the economic efficiency of enterprises is analyzed, the employee turnover cost and the economic benefit are predicted, and the mathematical relationship model is constructed. Simulation results show that, the system can analyze the employee turnover trend degree quantitatively, the employee turnover cost prediction accuracy is improved, and it can accurately describe the costs of economic growth and enterprise the decay of the economic impact. It can effectively grasp the company employee turnover limits and make the early warning, promote the company make related reform and rectification, and promote enterprise economic growth. It will have good application value in the field of human resources management.

\section{References}

[1] LI Feng, WU Chun- ming. Research on Prevention Fluctuation Control method of Network Intrusion Based on Energy Management[J]. Computer simulation, 2013,30(12): 45-48, 335.

[2] Alfaro V M, Vilanovab R. Robust tuning of 2DoF five-parameter PID controllers for inverse response controlled processes[J]. Journal of Process Control, 2013,23(4): 453-462.

[3] LUO Liang, WU Wen-Jun, ZHANG Fei. Energy Modeling Based on Cloud Data Center[J]. Journal of Software, 2014,25(7):1371-1387.

[4] HESAMZADEH M R, BIGGAR D R. Computation of extremal-Nash equilibria in a singlestage MILP[J]. IEEE Transaction on Power System, 2012, 27(3): 1706-1707.

[5] Song Minghong, Yu Huafeng, Chen Haiyan. Application of Improved Quantum Evolutionary Algorithm in Computer Network’s Routing Choice[J]. Bulletin of Science and Technology, 2014,30(1):170-173. 